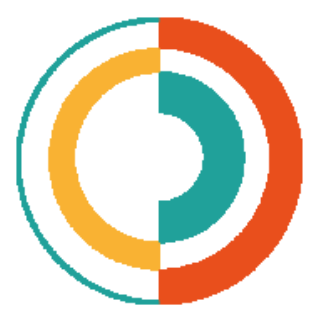

\title{
Para uma pedagogia da leitura realizada on-line: para construir conhecimento
}

\section{Towards a pedagogy of online inquiry reading}

\author{
Íris Susana Pires Pereira ${ }^{\mathrm{a}}$ \\ a Instituto da Educação da Universidade do Minho, Braga, Portugal - iris@ie.uminho.pt
}

\section{Palavras-chave: Multiletramentos. Internet. Leitura. Multimodalidade. Pedagogia.}

\section{Keywords:}

Multiliteracies. Internet. Reading. Multimodality. Pedagogy.
Resumo: O principal propósito deste artigo é o de evidenciar a necessidade da implementação de uma pedagogia específica da leitura realizada na internet com vista à construção de conhecimento. Situo genericamente esta ideia na teoria dos multiletramentos e arrolo três argumentos. Em primeiro lugar, apresento dados referentes à leitura on-line realizada por crianças e adolescentes, que, entre outros aspetos, revelam que estes sujeitos realizam com frequência a prática de leitura na internet para construir conhecimento. Em seguida, sistematizo as principais premissas de um modelo teórico desenvolvido para captar as especificidades da leitura realizada on-line para aprender. Por fim, apresento a análise de uma lição disponível numa plataforma digital on-line especificamente desenvolvida para a promoção da construção de aprendizagens e que mostra a dificuldade que a construção de uma tal pedagogia pode constituir quando é realizada sem conhecimento pedagógico específico. Embora não perfazendo um conjunto exaustivo, esta sequência de argumentos constitui-se, na minha opinião, como um conjunto coerente de razões convincentes da necessidade de implementar uma pedagogia específica da leitura dos textos que são lidos na internet com vista à construção de conhecimento.

Abstract: The main purpose of this article is to highlight the need to implement a specific pedagogy of online inquiry reading. I generically situate this idea in the multiliteracies theory and add three arguments. Firstly, I present data related to online reading performed by children and adolescents, which, among other aspects, reveal that these subjects frequently practice reading on the internet to learn. Next, I systematize the main premises of a theoretical model developed to capture the main features of online reading to learn. Finally, I present the analysis of a lesson available on an online digital platform specifically developed for young users' knowledge construction. The analysis shows the difficulty that the construction of such a pedagogy can constitute when it is done without specific professional knowledge. Although not exhaustive, this sequence of arguments constitutes, in my opinion, a coherent set of compelling reasons for the need to implement a specific pedagogy of reading texts that are read online for learning. 


\section{INTRODUÇÃO}

O manifesto original da teoria dos multiletramentos, apresentado pelo New London Group (NEW LONDON GROUP, 1996; 2000), foi desenvolvido com base na ideia de que "O mundo estava mudando, os ambientes comunicativos estavam mudando e (...) o ensino e a aprendizagem do letramento teriam de mudar também" (COPE; KALANTZIS, 2009, p.165) ${ }^{\mathbf{1}}$. Alguns dos principais fatores determinantes da mudança social identificados pelo New London Group têm-se confirmado como marcas indeléveis do século XXI, nomeadamente a consolidação da economia da informação e o desenvolvimento imparável das tecnologias digitais de comunicação. É neste contexto que a teoria dos multiletramentos se tem vindo a consolidar como "uma agenda para o futuro da educação, reivindicando a implementação de processos e sistemas de aprendizagem em muito diferentes dos do passado recente" (KALANTZIS; COPE, 2012, p. 28), sendo a finalidade da nova pedagogia proposta a de preparar os cidadãos para os letramentos configurados pela nova realidade social.

A internet é um exemplo claro de um desenvolvimento tecnológico que configurou a emergência de inúmeras práticas de letramento (LEU et al., 2011; LEU; KINZER; COIRO; CASTEK; HENRY, 2013; LEU; FORZANI; RHOADS; MAYKEL; KENNEDY; TIMBREL, 2015; LEU; MAYKEL, 2016). Na verdade, a internet tornou-se na tecnologia digital preferencial de construção de conhecimento pela comunidade global (KALANTZIS; COPE, 2012; LEU et al., 2013; 2016; KERVIN, MANTEI; LEU,2018), assumindo-se que uma dimensão essencial dessa leitura é o fato de ser "tipicamente focalizada na resolução de um problema ou para responder a uma pergunta; isto é, para aprender alguma coisa sobre a qual se procura mais informação" (LEU; MAYKEL, 2016, p. 124). Neste texto, centro-me justamente neste tipo de leitura, defendendo a ideia de que o ensino e a aprendizagem da leitura para aprender na internet reclamam a dotação dos professores de um entendimento pedagógico específico para esse fim.

Nas três seções seguintes do texto, aduzo três argumentos que fundamentam a minha ideia. Em primeiro lugar, apresento dados referentes à leitura on-line realizada por crianças e adolescentes. Nessa seção, faço uso amplo (embora não exclusivo) de dados reportados em “TIC Kids Online Brasil”(NÚCLEO DE INFORMAÇÃO E COORDENAÇÃO DO PONTO BR, 2018) e "Global Kids Online Project" (BYRNE; KARDEFELT-WINTHER;

\footnotetext{
${ }^{1}$ Neste texto, todas as traduções são da minha responsabilidade.
} 
LIVINGSTONE; STOILOVA, 2016), que permitem a caraterização do tipo e da frequência de práticas de leitura realizadas na internet por crianças e jovens brasileiros, assim como de conclusões de estudos que denunciam a existência de diferentes tipos de dificuldades nessa leitura. Por si sós, estes dados justificam o desenho de uma pedagogia específica da construção dos sentidos representados on-line. Em seguida, sistematizo as linhas centrais de um modelo teórico da pedagogia da leitura realizada on-line para aprender formulado no âmbito da teoria dos multiletramentos. Para além de evidenciar as especificidades dessa leitura, tais como a multimodalidade, a interconectividade e a interatividade dos textos digitais lidos na internet, o modelo formula caminhos pedagógicos dentro dos principais processos de aprendizagem genericamente equacionados no âmbito da pedagogia dos multiletramentos. Esta seção pretende por isso mostrar que essa nova pedagogia já começou a ser teorizada. Por fim, apresento a análise de uma lição disponível numa plataforma digital on-line destinada a jovens e que visa explicitamente à promoção da construção de aprendizagens. A análise revela a riqueza potencial da prática, que é particularmente evidente nos textos digitais usados na lição, e a limitação do trabalho pedagógico que consta das tarefas de construção de significados propostas, apontando desse modo para a dificuldade que a construção da nova pedagogia pode constituir quando é realizada sem conhecimento específico. O artigo termina com a reafirmação da principal ideia defendida, equacionando possibilidades de investigação futuras.

\section{O QUE LEEM E COMO LEEM AS CRIANÇAS E JOVENS NA INTERNET}

Estima-se que um terço dos utilizadores da internet de todo o mundo sejam crianças e jovens (LIVINGSTONE; CARR; BYRNE, 2015). Os dados do projeto "Global Kids Online"(http://globalkidsonline.net/highlights-from-the-past-year-of-gko-research/) são muito reveladores a esse respeito. O projeto, da responsabilidade do "UNICEF Office of Research Innocenti e do Department of Media and Communications da London School of Economics", inquire utilizadores com idades compreendidas entre os 9 e os 17 anos, de dez países de todas as regiões do globo, nomeadamente Argentina, Brasil, Bulgária, Chile, Gana, Montenegro, Filipinas, Sérvia, África do Sul e Uruguai, com o fim de caracterizar suas percepções sobre quando e como o uso da internet contribui para a sua vida, oferecendo oportunidades e benefícios que contribuem para o seu bem-estar, bem como sobre quando e como os utilizadores percebem o seu uso como problemático, ampliando o risco de danos que prejudicam seu bem-estar. Em termos genéricos, a radiografia que foi feita da utilização da 
internet pelos inquiridos no Brasil, em 2017 (NÚCLEO DE INFORMAÇÃO ECOORDENAÇÃO DO PONTO BR, 2018), confirma as conclusões da investigação de outros países. Em função do assunto deste texto, destaco as conclusões relativas à frequência, ao tipo de atividade e às competências de utilização da internet para a construção de aprendizagem que os utilizadores afirmam possuir. Assim, no relatório pode ler-se que

A pesquisa TIC Kids Online Brasil estima que, em 2017, 85\% das crianças e adolescentes com idade entre 9 e 17 anos eram usuários de internet no país. Em números absolutos, esse percentual corresponde a 24,7 milhões de indivíduos conectados nessa faixa etária. (p.24)

O relatório revela que a frequência com que esses utilizadores acedem diariamente à rede vem aumentando para " $88 \%$ em 2017, quando $71 \%$ das crianças e adolescentes declararam utilizar a internet mais de uma vez por dia” (p. 130). O relatório também confirma a ideia de que os utilizadores revelam atitudes muito favoráveis para com o papel da internet nas suas vidas futuras. Tal como se concluiu acerca de outros países, estes números também permitem inferir que a internet pode efetivamente estar a ter implicações significativas na vida das crianças brasileiras (cf. BYRNE et al., 2016).

O relatório é igualmente revelador do tipo de atividades que esses utilizadores realizam online. $\mathrm{Na}$ página que apresenta os dados em inglês (http://globalkidsonline.net/brazilianfindings-2017/; acesso no dia 19 setembro 2019), afirma-se que as atividades de uso da internet para comunicação e entretenimento são dominantes entre os inquiridos, como, por exemplo, enviar mensagens instantâneas (79\%), ver vídeos on-line (77\%), escutar música $(75 \%)$ e usar as redes sociais (73\%), que estão entre as mais populares. Contudo, a pesquisa também revela que outra atividade comum é a de pesquisar informação na internet, quer para realizar trabalho escolar (76\%), quer para perseguir interesses pessoais (64\%). Por conseguinte, esses resultados permitem concluir que a internet, no Brasil, é usada para apoiar a construção das aprendizagens dos alunos através da realização de diferentes tipos de práticas e de leitura de diferentes textos, muito embora o relatório também mostre que a escola falhe muito frequentemente em providenciar esse acesso nas aulas, com maior prejuízo para as crianças de contextos familiares menos favorecidos, que não têm a oportunidade de personalizar a sua aprendizagem em suas casas:

"Apesar da internet estar presente em praticamente todas as escolas brasileiras em áreas urbanas, tanto as públicas quanto as privadas, o uso da rede nem sempre está disponível aos alunos", conforme revela a pesquisa TIC Educação (CGI.br, 2018b). 
A TIC Kids Online Brasil 2017, por sua vez, aponta que pouco menos de um terço $(30 \%)$ das crianças e adolescentes declarou ter utilizado a internet em ambiente escolar, proporção que foi ainda menor entre aqueles das classes DE [socialmente mais desfavorecidas] (24\%), que poderiam se beneficiar da oferta de conexão de internet nas escolas dada a baixa penetração de conexão em seus domicílios. (p.132133)

Por fim, destaco uma outra conclusão geral da pesquisa, nomeadamente a de que uma percentagem alta de crianças e jovens utilizadores da internet acreditam possuir as habilidades informacionais para fazer sentido com (e de partilhar) a informação disponível na internet (70\%), incluindo a de definir palavras para as pesquisas (84\%), embora se declarem menos confiantes na avaliação da fiabilidade da informação disponível (62\%). Na verdade, a falta de habilidades digitais foi reconhecida e indicada como razão para o não uso da internet "por $6 \%$ das crianças e adolescentes de 9 a 17 anos, em especial, por aqueles pertencentes às classes DE (14\%) e na faixa etária de 9 a 10 anos (14\%)" (p.125). Os dados da pesquisa revelam ainda que não são os educadores/professores que ajudam os jovens utilizadores a ultrapassar os limites da sua competência ("as crianças e adolescentes nem sempre contam com os familiares ou educadores em sua socialização nos ambientes digitais" (p. 25)), o que significa que os utilizadores desenvolvem a sua competência sobretudo com a sua experiência: "de forma geral, a pesquisa revela que a maior parte das atividades consideradas no estudo apresenta percentuais mais altos de realização à medida que aumenta a idade dos usuários” (p. 135).

De entre as conclusões deste estudo, a menos consensual diz justamente respeito às percepções dos utilizadores sobre as suas habilidades digitais informacionais, na medida em que outras investigações revelam a existência de dificuldades efetivas na sua capacidade de utilização da informação disponível na internet para construir aprendizagens (LEU et al., 2013). Por exemplo, Danby e Davidson (2019) referem pesquisas que mostram dificuldades na definição e utilização de palavras na pesquisa, sobretudo no caso de procura de informação complexa. Os estudos que citam mostram que, na verdade, as pesquisas realizadas são muitas vezes 'desfocadas' (demasiado genéricas ou demasiado restritas), sendo frequentemente não planeadas. Mostram também dificuldade na seleção da informação relevante, que muitas vezes é feita de forma apressada, "limitando a sua pesquisa à primeira página dos resultados e frequentemente ao primeiro resultado da lista" (DANBY; DAVIDSON, 2019, p. 403), sendo superficial e não criteriosa. Os estudos citados mostram também a existência de dificuldades na compreensão da informação selecionada. Contudo, os autores referem outras investigações que dão conta de resultados positivos de intervenções pedagógicas especificamente 
desenvolvidas para ensinar utilizadores jovens a ultrapassar dificuldades (KROUSTALLAKI; KOKKINAKI; SIDERIDIS; SIMOS, 2015). Também Wolf (2016) cita investigação que mostra como o treinamento adequado e a aprendizagem podem superar as dificuldades causadas pela propensão para distração dos leitores perante os múltiplos estímulos envolvidos na leitura on-line (JIMURA; CAZALIS; STOVER; POLDRACK, 2014).

Vejo estes dados, que apontam para uma prática massiva e problemática da leitura na internet para aprender, como uma instanciação clara da chamada geral do New London Group para uma nova pedagogia dos multiletramentos. Kervin et al. (2018) defendem mesmo que a aprendizagem da leitura realizada na internet para aprender deveria assumir uma posição central no atual currículo escolar. Na seção seguinte, dou conta de um modelo teórico do "que ensinar e do como ensinar" a ler na internet para aprender.

\section{O QUE E COMO ENSINAR A LER NA INTERNET PARA CONSTRUIR CONHECIMENTO}

Nesta seção apresento, em linhas gerais, uma pedagogia específica da leitura realizada na internet para aprender (PEREIRA, no prelo). A sistematização que ofereço dá conta das principais caraterísticas que a leitura assume na internet e que a distingue da leitura tradicional (analógica) como base da definição da nova pedagogia (LEU et al., 2013). A conceptualização explora a definição do objeto e dos processos pedagógicos propostos pela teoria dos multiletramentos (NEW LONDON GROUP, 1996; 2000; KALANTZIS; COPE, 2012), apesar de incorporar contributos de teorias específicas desenvolvidas para a leitura realizada off-line.

O QUE ENSINAR NUMA PEDAGOGIA DA LEITURA ON-LINE PARA CONSTRUIR CONHECIMENTO

A aprendizagem da leitura sempre foi uma dimensão central de qualquer currículo escolar. $\mathrm{Na}$ minha opinião, esta tradição - e o saber teórico que a sustenta - continua a ser relevante nas propostas de definição dos conteúdos específicos associados à aprendizagem da leitura realizada na internet para aprender. $\mathrm{Na}$ generalidade dos casos, os textos que se leem na internet continuam a fazer uso da linguagem escrita e, nessa medida, ler on-line continua a ser um processo de construção de sentidos que implica a ativação dos diferentes tipos de 
processos cognitivos. A leitura on-line envolve, por exemplo, o reconhecimento de palavras escritas, o parsing sintático ou o reconhecimento de gêneros textuais, processos cognitivos básicos na leitura "analógica"; envolve, além disso, processos de ordem superior na configuração de sentidos profundos. Por exemplo, ler profundamente um texto implica a realização de inferência de sentidos, a análise crítica da informação do texto, o desenvolvimento de analogias, a identificação de perspectivas, a mobilização e a integração de experiências pessoais e do conhecimento prévio e a formação de imagens mentais (WOLF, 2016). Ler implica igualmente a ativação de processos metacognitivos, tais como o monitoramento dos processos anteriores e a resolução de eventuais problemas ao nível dos processos básicos e superiores (IRWIN, 2007) assim como o seu controle para gerar ideias e conhecimento novo (WOLF, 2016; IRWIN, 2017). Essencialmente, o primeiro grupo de habilidades conduz o leitor na construção de significados literais; o segundo leva-o para além das palavras, proposições e estruturas textuais até outros significados pessoais, emocionais e refletidos; o último assegura ao leitor o controle estratégico do processo de construção dos significados que são potencialmente novos e a sua integração nos esquemas de conhecimento. Nos contextos de leitura on-line, estes processos têm, por conseguinte, de continuar a fazer parte dos conteúdos de uma pedagogia da leitura realizada na internet para aprender. É, todavia, amplamente reconhecido que a leitura que é feita on-line expande ou renova o conjunto de habilidades e estratégias esperadas de um leitor competente (MILLS, 2010; ROWSELL; KRESS; PAHL; STREET, 2013; LEU et al., 2013; WALSH, 2006; 2008).

Com efeito, as práticas de letramento realizadas na internet envolvem a utilização de novos ou renovados gêneros textuais, como vídeos, mensagens, jogos, entre muitos outros, cada um situado em novas práticas sociais com finalidades específicas e, desse modo, apresentando padrões de organização da informação diferenciados e muito específicos (MILLS, 2010; 2016). A emergência de novos gêneros textuais digitais é na verdade evidenciada no conjunto de dados referentes às práticas de leitura na internet apresentados na seção anterior. Creio, por isso, que os gêneros textuais especificamente utilizados nas práticas de leitura realizadas online para aprender devem formar parte dos conteúdos da nova pedagogia da leitura. Contudo, aprender a construir sentido com esses textos envolve muito mais do que aprender a lidar com estruturas textuais e com as palavras escritas. Com efeito, os desenvolvimentos técnicos dos media digitais têm reconfigurado e mesmo transformado algumas caraterísticas dos textos que são lidos on-line (quando comparados aos textos impressos). Considero essas novas características igualmente incontornáveis na definição de uma pedagogia de leitura que se 
realiza on-line para aprender.

A multimodalidade é uma das caraterísticas textuais mais destacadas dos textos disponíveis on-line (JEWITT, 2005; 2008; KRESS, 2010; ROWSELL et al., 2013; SERAFINI, 2014; WALSH, 2006; 2008). No contexto da teoria semiótica que sustenta o conceito, os modos são os recursos materiais de construção de significado socialmente moldados e culturalmente disponibilizados (KRESS, 2010). Nos contextos de comunicação digital, os modos intencionalmente usados para representar e comunicar significados são, para além dos constituídos pela linguagem oral e escrita, a imagem estática e a imagem em movimento, a cor, o som, a música, o layout da página, entre outros. Em função desta realidade, os textos digitais têm sido descritos como unidades multimodais (multimodal ensembles) (KRESS, 2010) desenhadas de acordo com os potenciais de significação específicos de cada modo, cada um contribuindo de forma singular para a construção de uma unidade semiótica coerente e complexa. Este entendimento semiótico da representação multimodal de sentidos permite compreender que a leitura de textos on-line demanda a aprendizagem de habilidades de significação exigidas pela utilização desses outros modos (para além das necessárias para fazer sentido com o modo verbal escrito), desempenhando por isso um papel crucial na definição do que ensinar numa pedagogia da leitura on-line para aprender. Esta assunção está novamente alinhada com o que tem sido defendido no âmbito da teoria dos multiletramentos, de acordo com a qual o vasto conjunto dos recursos modais deve constituirse como conteúdo de aprendizagem (COPE; KALANTZIS, 2009; KLANTZIS; COPE, 2012). A teoria dos multiletramentos defende a aprendizagem dos "padrões e (d)as convenções de representação" (COPE; KALANTZIS, 2009, p. 175) dos modos de representação usados nos textos, de modo a dotar os leitores dos textos digitais da capacidade de os orquestrar na construção de significados coerentes (KRESS, 2010).

Outra particularidade significativa dos textos on-line reside na sua interconectividade, já que os hiperlinks tornam os textos on-line potencialmente ilimitados (LEMKE, 2002). Esse fato tem novamente impacto nas habilidades necessárias para ler e construir sentido com os textos digitais e, por conseguinte, na definição dos conteúdos de uma pedagogia da leitura realizada na internet para aprender. A natureza multidirecional de muitos textos que se leem na internet (WALSH, 2006) complica consideravelmente a configuração do "caminho de leitura" (que deixa de ser linear) e a definição do texto que é finalmente lido. Isso significa que a autodeterminação e o monitoramento se tornaram processos absolutamente essenciais ao 
navegar on-line a fim de aprender (COIRO, 2011; ROWSELL et al., 2013; WOLF, 2016). Para fazer isso bem, os leitores on-line precisam de desenhar conscientemente para si mesmos um plano de leitura específico, com objetivos claros, adotar atentamente procedimentos estratégicos, como localizar, selecionar, reorganizar e sintetizar as informações relevantes para seus propósitos específicos (LEU et al., 2013), para construir o seu caminho de leitura e, além disso, de avaliar o resultado de seu plano de leitura em função dos objetivos que o desencadearam (COIRO, 2011). Isso é necessário para finalmente chegar à construção de conhecimento coerente e relevante para aprender (LEU et al. 2013). Considero esse procedimento estratégico outro aspecto importante do conteúdo de uma pedagogia da leitura que é realizada on-line para aprender, fato que também encontra apoio empírico nas dificuldades reveladas nos estudos revistos na seção anterior.

Outra dimensão dos textos digitais on-line é a sua natureza potencialmente não editada, bem ilustrada pela atual proliferação de "notícias falsas", tornando essencial que os leitores interroguem constantemente a precisão e a fiabilidade da informação de qualquer texto encontrado na internet. No entanto, além da necessidade de um tal pensamento crítico, a teoria dos multiletramentos também reclama a adoção pedagógica de princípios fundamentais do chamado letramento crítico. Basicamente, de acordo com esta perspectiva, os textos são vistos como construtos socioculturalmente situados - portanto, nunca neutros -, exigindo dos leitores o desenvolvimento de uma vigilância constante dos interesses sociais que estão a ser atendidos e o posicionamento ideológico assumido para os próprios leitores (GEE, 1996; LUKE; O'BRIEN; COMBER 2001; CERVETTI; PARDALES; DAMICO, 2001). A capacidade de identificar, resistir e superar perspectivas imprecisas ou tendenciosas tornou-se numa competência essencial para a economia da informação (KALANTZIS; COPE, 2012). A meu ver, essa atitude profundamente crítica constitui um pressuposto central na "mudança de pedagogias para os novos tempos", concebidas para "envolver os alunos na interpretação, análise, crítica e produção de textos em contextos públicos" (LEWIS; TIERNEY, 2011, p. 320; COIRO, 2015; WOLF, 2016), portanto outra dimensão essencial do conteúdo da pedagogia da leitura que é realizada on-line para aprender. E, na verdade, essa necessidade foi expressa pelas próprias crianças que participaram na pesquisa "Kids Online”.

COMO ENSINAR NUMA PEDAGOGIA DA LEITURA REALIZADA ON-LINE PARA APRENDER 
Na teoria dos multiletramentos, educar indivíduos com habilidades necessárias à cidadania do século XXI depende crucialmente da disponibilização de contextos de aprendizagem desenhados de acordo com um repertório de processos básicos de aprendizagem (NEW LONDON GROUP, 1996; 2000; KALANTZIS; COPE, 2012; JEWITT, 2008; LIM, 2018)). Assume-se que esse repertório é central na produção de "conhecimento mais profundo, mais amplo, mais confiável, mais perspicaz e mais útil” (KALANTZIS; COPE, 2012, p. 249). O repertório envolve "aprender fazendo e pensando" (p. 25) e reconcilia processos como "experimentar o conhecido e o novo"; "conceituar nomeando e com teoria"; "analisar funcional e criticamente"; e "aplicar de forma adequada e criativa". Tal como tento explicar em seguida, estes são processos de aprendizagem fundamentais na definição da pedagogia da leitura que nos interessa neste texto.

Assim, assume-se que "experienciar" é a base da aprendizagem (DEWEY, 1916). Essencialmente, ao "experienciar o conhecido", as necessidades, identidades, expectativas, aspirações, interesses e motivações dos alunos fornecem um ponto de partida para a nova aprendizagem, enquanto ao "experienciar o novo" os alunos são imersos em "novas informações factuais e experimentam coisas novas" (KALANTZIS; COPE, 2012, p. 243244). A meu ver, numa pedagogia da leitura on-line para aprender, experienciar inclui práticas de leitura nas quais os leitores criam significados (antigos e novos) em tarefas de leitura na internet social e culturalmente desenhadas pelos professores e que ativam tacitamente habilidades e estratégias de relevantes.

"Conceituar" refere-se ao conhecimento abstrato que é conscientemente construído pelos alunos (VYGOTSKY, 1979; 1986). Ao conceituar pela nomeação, "os alunos esclarecem, classificam, agrupam e distinguem" (KALANTZIS; COPE, 2012, p. 245), definindo termos. Ao conceituar com a teoria, eles tornam-se criadores ativos de teoria, permitindo-lhes “descrever claramente padrões no mundo" (p. 245). Considero que, numa pedagogia da leitura on-line para aprender, a conceituação acontece quando os alunos desenvolvem conhecimento explícito e específico sobre esse tipo de leitura, conforme discutido anteriormente: por exemplo, sobre a natureza multimodal dos textos e sobre as estratégias específicas de leitura, bem como uma metalinguagem adequada à construção do seu próprio entendimento do que a leitura que se realiza na internet para aprender de fato é e envolve. 
"Analisar" refere-se ao uso do conhecimento conceitual dos alunos para deliberadamente fazer sentido (isto é, mais sentido) com o que é experienciado. Ao analisar funcionalmente, os alunos usam conhecimento especializado para desenvolver cadeias de raciocínio, inferir e prever conhecimentos (KALANTZIS; COPE, 2012, p. 246-247). Ao analisar criticamente, os alunos avaliam interrogando "os interesses, motivos e ética que podem motivar as reivindicações de conhecimento... um processo sempre vigilante de reflexão sobre propósitos e interesses" (p. 247). Mais uma vez, entendo que, no caso da uma pedagogia da leitura realizada na internet, a análise funcional orienta os alunos na utilização do seu conhecimento conceitual para descrever padrões de linguagem e suas funções na construção do significado, bem como na consciencialização das habilidades e estratégias que eles usaram para fazer sentido, aprofundando assim a compreensão desses conhecimentos específicos. Além disso, assumo que a análise crítica guia os leitores além dos significados representados, por exemplo, examinando as fontes ou desvelando as suposições ideológicas ocultas nos textos, entendendo e apreciando como elas são transmitidas através da manipulação dos modos de representação.

Finalmente, "aplicar" supõe um retorno ativo à experiência, permitindo ao aluno a possibilidade de usar o que foi aprendido em novas práticas de criação de significado (DEWEY, 1938). "Aplicar de forma apropriada" é um processo pelo qual o conhecimento "é desenhado para realizar as tarefas" (KALANTZIS; COPE, 2012, p. 248) nas situações reais do mundo ou simuladas na escola, enquanto que ao aplicar de forma criativa "tentamos dar grandes saltos. Pegamos o conhecimento de um contexto e aplicamo-lo num contexto muito diferente" (p. 249). Ao aprender a ler on-line, este passo final envolve o aluno em novas situações informadas de criação de significado, incluindo a leitura de novos textos multimodais e hiperconectados e a criação de novos textos para se comunicar com os outros (LEU et al., 2013).

Na teoria dos multiletramentos, os contextos de aprendizagem são vistos como envolvendo alunos em sequências colaborativas de ações significativas e realisticamente complexas (KALANTZIS; COPE, 2012, p. 274). Supõe-se que quanto mais amplo for o conjunto de processos de conhecimento envolvido num projeto de aprendizagem, independentemente da ordem em que são realizados, mais fundamentado será o conhecimento construído. Assumese, igualmente, que é importante que os contextos da aprendizagem tenham organização genérica intencional, "uma sequência de ações que possuem uma estrutura narrativa" (p. 261), 
desdobrando-se em "orientação" (na qual é definido um objetivo de aprendizagem ou uma pergunta estimulante) -“jornada” (conjunto preparado de atividades de aprendizagem) "destino" (no qual a aprendizagem é compartilhada ou colocada em uso).

Ao argumento factual de que os jovens não sabem fazer bem a leitura na internet para aprender acrescentei agora um argumento teórico que avança linhas centrais de uma pedagogia específica para ensinar essa leitura, desenvolvida no quadro da teoria dos multiletramentos. Faz, por isso, agora todo o sentido perguntar-se sobre a implementação prática dessa pedagogia. $\mathrm{Na}$ seção seguinte, apresento e analiso um caso que é revelador da complexidade da materialização dessa nova pedagogia.

\section{QUANDO O CONHECIMENTO PEDAGÓGICO EXISTENTE DEIXA DE SER SUFICIENTE}

Perante a falta dos conhecimentos e capacidades de leitura necessários para ler na internet para aprender, Kroustallaki et al. (2015) recomendam o desenvolvimento intencional de instrumentos de pesquisa on-line específicos para os utilizadores mais jovens, que ofereçam âmbitos de pesquisa do seu interesse e pistas de pesquisa suficientemente andaimadas para amparar o seu trabalho e aprendizagem (DUARTE TORRES;WEBER; HIEMSTRA, 2014; LEU et al., 2013). Creio que os investigadores têm aqui em mente a exploração de plataformas digitais de aprendizagem para ensinar os alunos a ler na internet. Com efeito, as plataformas digitais de aprendizagem são uma evidência clara das novas práticas sociais que surgiram com a internet. Ao fazer uso dos recursos fornecidos por um ambiente on-line, essas plataformas oferecem práticas que ampliam "possibilidades de acesso e participação, expandindo o leque de possíveis instrutores e alunos, bem como o leque de recursos semióticos disponíveis para desenhar ambientes de aprendizagem" (BEZEMER; KRESS, 2016: 120). A plataforma TED-Ed é um desses casos.

TED-Ed é uma plataforma internacional de acesso aberto promovida pela fundação TED (Tecnologia, Entretenimento, Design), sendo apresentada como apartidária, sem fins lucrativos e dedicada a "espalhar ideias" (https://ted.com/about/our-organization). A plataforma TED-Ed foi desenvolvida especificamente com vista à prática pedagógica, uma intenção evidente no subtítulo "Lições que vale a pena partilhar", na afirmação de que "Tudo o que fazemos apoia a aprendizagem" e no reconhecimento de que está a servir atualmente 
"milhões de professores e alunos em todo o mundo todas as semanas" (https://ed.ted.com/about).

A plataforma oferece milhares de "lições" e "séries", que são lições organizadas em temas, destinadas a alunos com mais de 13 anos de idade. Cada lição segue um projeto geral de aprendizagem desencadeado por um desafio e envolve a leitura de textos multimodais hiperligados, oferecendo tarefas de compreensão e um fórum que permite que os alunos compartilhem a sua compreensão. Cada lição pode ser acedida on-line por um público-alvo (por exemplo, uma turma de alunos), em cujo caso a lição é um suporte para maior construção da aprendizagem (na aula, por exemplo). As lições TED-Ed são originalmente desenvolvidas pela equipa TED-Ed, mas também podem ser criadas por usuários (ou seja, professores e alunos), sendo neste caso necessário personalizar uma "lição original" ou seguir o modelo fornecido para gerar uma nova lição.

Ao navegar pela primeira vez nesta plataforma, constatei que as lições TED-Ed são simuladoras da leitura que se faz on-line para aprender. Relacionei de imediato esta plataforma com as recomendações de Kroustallaki et al. (2015) acerca do desenvolvimento de plataformas pedagógicas para leitores jovens, tendo, por isso mesmo, a plataforma emergido como um laboratório de pesquisa da praticabilidade da pedagogia anteriormente apresentada. O estudo de caso (STAKE, 2000) que realizei de uma lição em particular foi muito revelador a este respeito (PEREIRA, no prelo).

A lição em questão intitula-se "O que significa ser um refugiado?”, um original desenvolvido por uma equipe de editor de roteiro, realizador, artista de animação, compositor, designer de som e dois pedagogos. Pode ser acedida em http://ed.ted.com/lessons/what-does-it-mean-tobe-a-refugee-benedetta-berti-and-evelien-borgman. Selecionei esta lição devido ao seu significado social, na esperança de que isso pudesse aumentar seu potencial pedagógico. A minha análise mostrou que, na lição analisada, há momentos de claro alinhamento pedagógico com a abordagem teórica apresentada na seção anterior, mas também existem muitos casos de afastamento dessa mesma teoria.

\section{A LIÇÃO}


Um dos aspectos mais interessantes da pedagogia da leitura on-line implementada nesta lição diz respeito à sua organização genérica, que parece exemplificar o caminho narrativo de aprendizagem sugerido por Kalantzis; Cope (2012). Como gênero pedagógico, a lição segue o padrão de cinco seções que é comum a todas as lições TED-Ed (cf. Figura 1), sendo possível perceber que está organizada em “orientação - jornada - destino”.

Fig. 1 - Organização genérica da lição.

\section{What does it mean to be a refugee? - Benedetta Berti and Evelien Borgman}

\section{Let's Begin...}

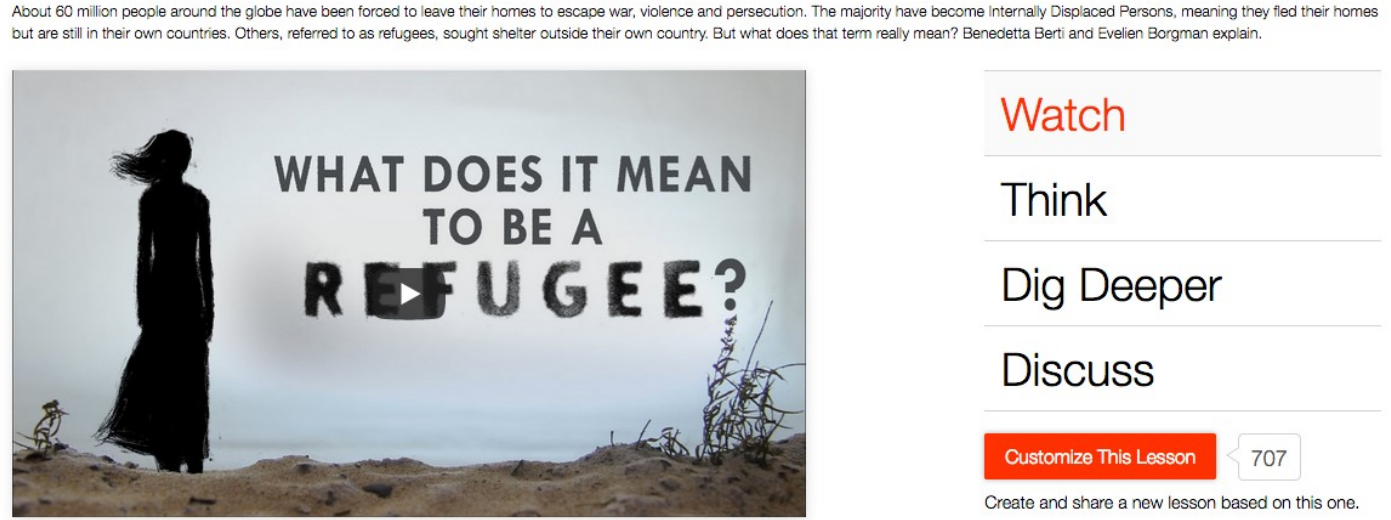

FONTE: http://ed.ted.com/lessons/what-does-it-mean-to-be-a-refugee-benedetta-berti-and-evelien-borgman

A lição é introduzida por "Vamos começar..." (Let's Begin ...), um parágrafo que apresenta diretamente no tópico a ser abordado no vídeo subsequente e que coloca uma pergunta concreta que serve de "orientação" para a jornada de aprendizagem. O momento seguinte é a seção "Veja" (Watch), que oferece um vídeo animado com a opção de legendas em diferentes idiomas. Segue-se lhe, por sua vez, a seção "Pense" (Think), que inclui um conjunto de tarefas de compreensão com foco nos significados representados no vídeo. "Aprofunde" (Dig Deeper) é a seção seguinte, que oferece um texto com hiperlinks que, conforme indicado no título "Recursos adicionais para você explorar", fornece aos alunos informações adicionais relevantes sobre o tópico. "Veja", "Pense" e "Aprofunde" podem ser vistos como "a jornada". Por fim, os alunos têm a possibilidade de entrar num fórum que lida com o problema em estudo na seção "Discuta" (Discuss) e que atua efetivamente como o "destino" da aprendizagem. Como tal, a estrutura desta lição apresenta-se como um ambiente de aprendizagem que oferece aos alunos uma simulação da leitura para aprender que eles frequentemente realizam na internet. 


\title{
"VAMOS COMEÇAR"
}

Esta seção é composta pelo seguinte parágrafo:

\begin{abstract}
Cerca de 60 milhões de pessoas em todo o mundo foram forçadas a deixar as suas casas para escapar da guerra, violência e perseguição. A maioria tornou-se "Pessoas Internamente Deslocadas", o que significa que fugiram de suas casas, mas ainda estão em seus próprios países. Outros, chamados de "refugiados", procuraram abrigo fora de seu próprio país. Mas o que é que esse termo realmente significa? Benedetta Berti e Evelien Borgman explicam.
\end{abstract}

A questão que encontramos nesta seção justifica ainda mais a caracterização desta lição como um exemplo de prática de leitura para aprender, uma vez que identifica especificamente um termo como o alvo da aprendizagem. O parágrafo orienta os leitores para uma experiência intencional de leitura com vista à construção do conhecimento necessário para responder a essa pergunta. A prática da leitura envolve, portanto, componentes-chave da pedagogia apresentada na seção anterior, nomeadamente a autodeterminação e a existência de objetivos claros de leitura (LEU et al., 2013; COIRO, 2011). Este parágrafo permanece como frame de toda a lição, transmitindo a ideia de que cada momento constituiu um passo desenhado para levar os usuários à construção de conhecimentos relevantes para chegar à resposta daquela pergunta.

"VEJA"

Esta seção é particularmente relevante para caracterizar a pedagogia da leitura adotada nesta lição. O vídeo disponibilizado é representativo dos novos textos multimodais que são frequentemente usados na prática de leitura on-line, tal como descrito na secção anterior deste artigo, e é anunciado como fonte de informação para responder à pergunta que guia a lição. $\mathrm{O}$ vídeo é claramente um multimodal ensemble, na verdade exemplar das instâncias e funções complementares dos diferentes recursos semióticos (modos e formas) usados para configurálo como um todo coerentemente orquestrado (KRESS, 2010). O vídeo tem duas camadas principais de significado, a saber: uma sequência de imagens animadas (e sons) e um texto verbal.

O texto verbal é um gênero expositivo (MARTIN; ROSE, 2015), apresentando informações organizadas nas seguintes partes: definição histórica do conceito de refugiados (vs. migrantes); razões e dados (por exemplo, o número de crianças refugiadas); condições de 
viagem e recepção; e dificuldades de integração social. Este texto representa, de forma dominante, significados factuais fortemente ligados a uma voz impessoal e autoritária (HALLIDAY, 1994), apontando para a construção de um significado objetivo do que significa ser refugiado. A construção desse significado implica a ativação de processos cognitivos básicos de compreensão:

O mundo conhece refugiados há milênios (...). Hoje, aproximadamente metade dos refugiados do mundo são crianças, alguns deles não acompanhados por um adulto, uma situação que os torna especialmente vulneráveis ao trabalho infantil ou à exploração sexual. (...) A maioria das viagens de refugiados é longa e perigosa.

Todavia, a propósito da definição de refugiado, também se ouve/lê o seguinte: "Mas o direito internacional, de modo certo ou errado, apenas reconhece aqueles que fogem do conflito e da violência como refugiados". Este enunciado abre portas para a discussão dos fatos asseverados, além de desafiar o entendimento de que o que é verbalmente representado no vídeo é provavelmente apenas uma de entre várias perspectivas alternativas. Acresce que o final do vídeo é constituído por uma coda na qual é introduzida uma perspectiva pessoal histórica sobre o assunto com o seguinte enunciado: "Se você voltar à sua história familiar, é provável que descubra que, num determinado momento, os seus antepassados foram forçados a sair de casa, escapando de uma guerra ou fugindo da discriminação e da perseguição", com um último apelo enfático: "Seria bom lembrarmo-nos das suas histórias quando ouvimos falar de refugiados". Estes enunciados são diferentes porque demandam a construção de um significado intersubjetivo do significado de "refugiado" através da ativação explícita do conhecimento pessoal (ativação de processos cognitivos de ordem superior), sugerindo, assim, a importância dos significados reflexivos na resposta à pergunta central.

Este texto verbal poderia existir por si só, mas as partes animadas e auditivas entrelaçam-se com ele de maneira especialmente significativa. As imagens animadas representam uma narrativa organizada em segmentos de eventos que se desenrolam no tempo e no espaço, com uma cadeia inferível de razões e consequências das ações dos personagens (KRESS; VAN LEEUWEN, 2006). As imagens mostram a história não feliz das jornadas dos refugiados, sendo possível identificar uma mulher como a personagem principal. O vídeo também faz uso de palavras-chave escritas, como "refugiados", "deslocados" e "asilo". Este recurso ajudaria a dar sentido a este filme se ele fosse "mudo", mas o apoio do texto expositivo verbal torna a história mais clara. Além disso, cores (cinza-amarelo areia- bronze opaco - preto) e sons (incluindo tiros de armas, fogo crepitante e gritos de abutres) são recursos semióticos muito 
significativos (KRESS; VAN LEEUWEN, 2006), porquanto usados para criar um conjunto de significados muito poderosos. A Figura 2 é um shot de um momento no qual abutres negros são vistos e ouvidos pelos refugiados em um horizonte acinzentado, cujo valor simbólico é especialmente significativo em um contexto em que jornadas difíceis estão a ser referidas verbalmente.

Fig. 2 - Abutres vigiam as deslocações dos refugiados.

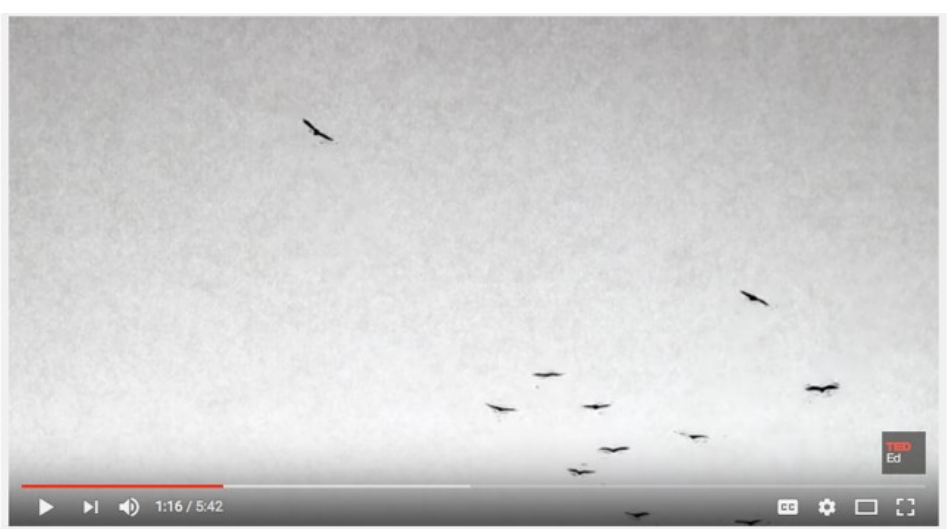

FONTE: http://ed.ted.com/lessons/what-does-it-mean-to-be-a-refugee-benedetta-berti-and-evelien-borgman

A Figura 3 é uma sequência de três shots que descrevem como o local de destino, imaginado como uma fortaleza de proteção, se torna num espaço compactado de tendas frágeis (e em um horizonte cromático escuro), significados esses que complementam as informações verbais ouvidas referentes às dificuldades encontradas ao chegar ao local de refúgio.

Fig. 3 - A decepção na chegada.
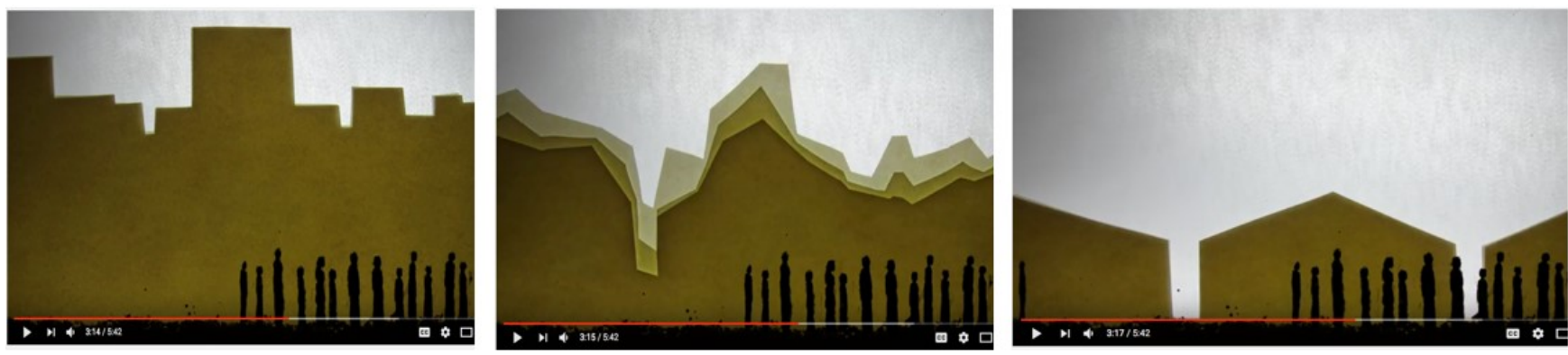

FONTE: http://ed.ted.com/lessons/what-does-it-mean-to-be-a-refugee-benedetta-berti-and-evelien-borgman

Outros códigos e significados são orquestrados nas imagens animadas, como a cadência lenta, mas regular da música, construindo claramente o significado do funcionamento de uma máquina e, assim, contribuindo para o significado de desumanização na história mostrada. 
Um elemento particularmente importante na construção do significado nessas imagens animadas é o olhar dos personagens assim como a proximidade e o ângulo entre os participantes, que criam significados referentes à relação entre o espectador e as personagens e que são fundamentais para entender esta história. Por exemplo, no início as imagens mudam de um close de pernas andando, para uma visão das mãos das pessoas e, em seguida, dos seus perfis e expressões fixas e não sorridentes (cf. dois primeiros shots da Figura 4). Isso posiciona o espectador como uma testemunha dos dramas dos refugiados, posição que se mantém quase até ao final do vídeo. Mas o conjunto final de imagens mostra os rostos dos refugiados olhando de frente, procurando contato visual conosco, os espectadores, mudando assim o nosso posicionamento: não somos mais testemunhas; somos chamados diretamente a nos envolvermos com o que estamos a testemunhar (cf. shot mais à direita da Figura 4). Como narrativa, essas imagens animadas solicitam empatia do visualizador, um significado subjetivo do que significa ser um refugiado a que se chega através da ativação de processos complexos de criação de sentido.

Fig. 4 - Variação na visualização das personagens: de espetadores a testemunhas.

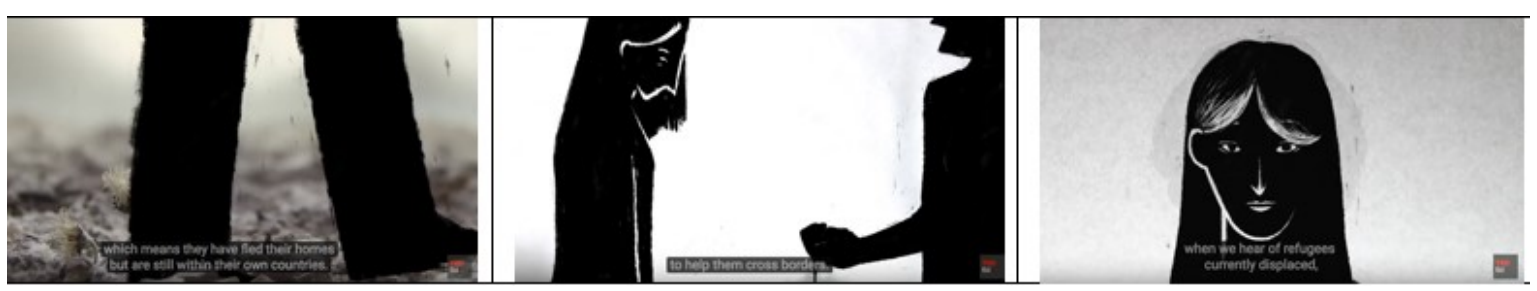

FONTE: http://ed.ted.com/lessons/what-does-it-mean-to-be-a-refugee-benedetta-berti-and-evelien-borgman

Como um multimodal ensemble, o vídeo realiza uma ação pragmática complexa sobre o leitor, oferecendo a negociação de um conjunto de significados diverso (factuais, controversos, experienciais, emocionais), que são potencialmente pertinentes para finalmente chegar a uma resposta bem desenvolvida à pergunta que orienta esta lição. Como ele sustenta a experiência de aprender (o conhecido e o novo), o vídeo desempenha um papel muito significativo no estabelecimento de um contexto de leitura potencialmente muito rico nesta lição. No entanto, o potencial dessa experiência de leitura para aprender é explorado pedagogicamente de forma muito decepcionante.

\section{"PENSE"}


Esta seção fornece um conjunto de oito tarefas de criação de significado relacionadas com o vídeo. Todavia, na maioria dos casos, as tarefas visam exclusivamente à mensagem verbal e de forma muito parcial, porque os alunos não são orientados para construir muitos dos significados representados no texto expositivo. Contra as expectativas, apenas os significados verbais objetivos são valorizados no trabalho proposto aos alunos. Não há espaço para significados subjetivos ou reflexivos, nem para nenhum raciocínio ou questionamento profundo, como se constata nas seguintes perguntas, referentes a significados explicitamente representados no texto verbal:

(2) Qual a diferença entre refugiados e pessoas deslocadas internamente?

(3) De acordo com a definição legal internacional, refugiado é alguém que

(4) Um requerente de asilo é

(5) Os países anfitriões têm várias obrigações para com os refugiados, como

A pergunta 1 ("Em todo o mundo, aproximadamente quantas pessoas foram forçadas a deixar suas casas para escapar da violência e da guerra?") é, de fato, respondida no parágrafo "Vamos começar..."; as perguntas 6 ("Pode explicar as diferenças e os traços comuns de refugiados e migrantes?”) e 7 (“Pense em uma família forçada a deixar seu país para fugir da guerra. Explique os principais obstáculos e desafios que eles podem enfrentar ao longo do caminho”) diferem minimamente desse padrão, pois podem ser respondidas reorganizando as informações encontradas explicitamente no texto verbal. A pergunta 8 ("O que as pessoas comuns podem fazer para ajudar famílias e indivíduos que se tornaram refugiados?”) não tem resposta no vídeo (embora presente na seção "Aprofunde”).

Em geral, a seção "Pense" oferece uma simulação muito restrita do que a leitura na internet para aprender realmente requer dos leitores. Apenas certos aspectos do conjunto multimodal estão abertos à indagação pedagógica, enquanto os significados representados pelas imagens animadas e pelo som estão fechados à inspeção dos alunos, permanecendo, portanto, invisíveis, apesar da sua inegável contribuição para os significados representados no vídeo e, certamente, para a experiência de criação de significado dos alunos quando o visualizam. A complexidade multimodal que encontramos nas imagens animadas é desvalorizada como fonte de informação, assim como a ativação de processos cognitivos para construção de significados complexos. Processos como identificação de perspectivas, ativação de conhecimento prévio, analogia, inferência, análise crítica, essenciais para a negociação e a

\footnotetext{
${ }^{2}$ Questões disponíveis na página TEDEd - What does it mean to be a refugee? - Benedetta Berti and Evelien Borgman que pode ser acessada através do endereço: https://ed.ted.com/lessons/what-does-it-mean-to-be-arefugee-benedetta-berti-and-evelien-borgman\#review
} 
reflexividade do significado... não estão no radar pedagógico. Há, portanto, uma lacuna visível entre o vídeo oferecido para construção de aprendizagem e os significados previstos nas tarefas propostas. O resultado é uma experiência de leitura muito restritiva. Além disso, não há "conceituação" em relação ao complexo processo de leitura em que os alunos estão envolvidos, evidente no fato de que nenhum recurso semiótico é tornado visível nas tarefas propostas.

\section{“APROFUNDE”}

Como não houve nenhuma tentativa de conceituar a leitura experienciada, não se pode esperar que esta seção se constitua numa maneira adequada de analisar esse mesmo processo. No entanto, oferece-se como momento para análise do conceito de "refugiado" através da leitura de um texto com hiperlinks. Contudo, a pedagogia de leitura que se materializa é novamente muito limitada.

"Aprofunde" oferece um texto organizado em duas partes. Uma consiste num conjunto de quatro parágrafos com links para diferentes textos de diferentes gêneros, incluindo relatos, histórias e uma entrevista, nos quais vozes detentoras de autoridade e vozes subjetivas falam sobre refugiados. A segunda parte é composta por mais quatro parágrafos, nos quais uma voz direta e impessoal fala com um tom assertivo e diretivo: "É importante perceber... ao mesmo tempo que devemos ter em mente...”, oferecendo opiniões e perspectivas que os leitores são levados a assumir sem discussão. Há também um link para um ensaio pessoal no qual alguém oferece sugestões de maneiras de ajudar os refugiados. Nesta seção, a única tarefa de aprendizagem explícita é a instrução para seguir os links para “Aprender mais...”; "Investigar mais..." (na primeira parte) e "Aqui você encontra algumas maneiras pelas quais pode ajudar e capacitar..." (na segunda parte), direcionando o leitor para uma construção totalmente autônoma de conhecimento.

Tal como na seção anterior, a experiência de leitura aqui envolve textos multimodais. No entanto, o foco das instruções para os leitores recai mais uma vez sobre o texto verbal, o que reforça a tendência encontrada na seção "Pensar". Além disso, embora várias informações sejam oferecidas com o potencial de fortalecer e ampliar o entendimento (ainda fraco) do aluno sobre os refugiados e extrair implicações sociais, nenhum suporte é oferecido para ajudá-lo a analisar criticamente sobre as informações (autorizadas, mas controversas) 
oferecidas. De fato, nenhuma ponte pedagógica é estabelecida entre as duas experiências de leitura (o vídeo e o texto com hiperlinks) e seus respectivos significados, o que a meu ver condiciona a capacidade de o aluno fazer convergir e reconciliar os dois. Mais uma vez, nenhuma tentativa é feita para "conceituar" ou tornar visível o complexo processo de leitura para o construtor de significados. Portanto, "Aprofunde" reforça a constatação anterior referente à restrição da pedagogia da leitura implementada.

\section{"DISCUTA"}

"Discuta" oferece uma oportunidade de aplicar o que foi aprendido na forma de escrita e partilha de entendimentos pessoais (LEU et al., 2013). Assume a forma de escrita de texto com o potencial de desenvolvimento uma percepção pessoal e, portanto, para consolidar aprendizagens. Acredito que esse seja, de fato, o objetivo desta seção da lição:

\footnotetext{
Os refugiados têm o direito de ser protegidos nos seus países anfitriões. Na sua opinião, os refugiados estão a ser adequadamente protegidos? Os refugiados também têm o direito de escapar da guerra e de buscar abrigo e segurança num país anfitrião, mas, na prática, fazer valer esse direito nem sempre é fácil. Os países anfitriões devem manter sempre as suas fronteiras abertas para os refugiados ou devem ser autorizados a estabelecer e aplicar cotas máximas?
}

No entanto, somos forçados a perguntar se os alunos já construíram conhecimento relevante suficiente para serem capazes de se envolver numa argumentação sustentada. Essas perguntas podem ser encaradas como puramente retóricas, uma vez que a própria lição sugere as respostas esperadas, sem oferecer espaço para reflexão autêntica e um posicionamento pessoal. E, apesar da relevância das perguntas avançadas para discussão, elas não regressam à pergunta inicial, que talvez devesse fazer parte do esperado "destino de aprendizagem".

Por conseguinte, nesta lição há um fosso entre a riqueza potencial da prática e a limitação do trabalho pedagógico que consta das tarefas de construção de significados (leitura) aí propostas. Com efeito, a análise desta lição permitiu-me constatar a complexidade da aplicabilidade da abordagem teórica antes apresentada. Sendo necessário dar respostas pedagógicas às dificuldades reveladas pelos alunos (cf. seção inicial do artigo) e havendo algumas teorias sobre o que e o como ensinar (cf. seção anterior do artigo), este exemplo mostra a dificuldade implicada no desenho das respostas pedagógicas práticas adequadas. Sendo verdade que o caminho de aprendizagem apresentado pela lição é organizado em torno de um objetivo para a leitura desde o início, oferecendo textos multimodais e interativos para 
representação de informações e partilha de conhecimento, aspectos muito valorizados no modelo de leitura apresentado, a lição como um todo mostra que a aplicação da teoria é difícil. Isso ficou particularmente evidente no tratamento pedagógico dos significados multimodalmente representados. A constatação do modo como a lição restringe o acesso dos leitores a todos os significados do texto on-line multimodal ecoa a seguinte discussão de Kress (2015) sobre o papel da multimodalidade na construção de abordagens pedagógicas textuais "completas":

Se o objetivo do ensino do letramento fosse apoiar a comunicação em sua forma "completa", o discurso e a escrita precisariam de ser ensinados como parte de conjuntos [multimodais]. Os currículos e práticas de ensino precisariam ser adaptados. Sem a consciência da [multimodalidade], temos algumas peças de um quebra-cabeça, sem saber quais são e quais podem ser necessárias para entender o todo (KRESS, 2015, p.58).

Contudo, a meu ver, o desalinho observado entre a lição e a pedagogia não pode ser interpretado como revelador de limitações na própria plataforma, da mesma forma que seria errado assumir que se deve a uma impraticabilidade da abordagem teórica (relativa à pedagogia da leitura on-line para aprender). Na minha opinião, a plataforma TED-Ed oferece um potencial excepcional para a concretização de tal pedagogia. Quero com isto dizer que a teoria seria praticável nesta plataforma. As lições são experiências intencionais de criação de significado baseadas na leitura de textos multimodais interconectados. E seria possível melhorar as propostas oferecidas à luz da teoria proposta. Por exemplo, há aqui margem para tarefas que orientem os leitores na reconciliação (síntese) dos significados emocionais e factuais, envolvidos na definição de "refugiado", representados nas imagens animadas e no modo verbal (oral ou escrito) e, depois, na reconciliação desses significados com os representados no texto com hiperlinks; seria também possível criar tarefas que oferecessem a possibilidade de os alunos desenvolverem uma consciência de seu processo de criação de significado, por exemplo, chamando sua atenção para os modos envolvidos na representação dos diferentes significados construídos. Ao fazer isso, os alunos seriam desafiados a construir "esquemas conceituais cada vez mais sofisticados" (KALANTZIS; COPE, 2012, p. 274) sobre como se lê na internet para aprender. As tarefas também poderiam ser desenhadas para chegar a perspectivas controversas e até opostas, para que os alunos desenvolvessem a capacidade de analisar criticamente os textos on-line. Finalmente, os alunos poderiam ter a possibilidade de comunicar significados de maneiras criativas que envolvessem outros modos além da linguagem verbal escrita. Nenhuma dessas possibilidades foi, contudo, explorada. 
Sustento, isso sim, que a fonte das restrições observadas decorre das concepções pedagógicas que estiveram na gênese da construção desta lição, que considero incoerentes com a pedagogia da leitura on-line para aprender apresentada na seção anterior. Um princípio central da teoria dos multiletramentos é a assunção dos professores como "designers de ambientes de produção de conhecimento, construtores de andaimes de aprendizagem, gerentes de aprendizagem de alunos e pesquisadores de desempenho de aprendizes" (KALANTZIS; COPE, 2012, p. 71). No entanto, os educadores que elaboraram esta lição parecem estar trabalhando num contexto totalmente novo de criação de significado usando "velhas e limitadas" teorias sobre a leitura e a sua pedagogia. Simplificando, eles parecem não ter o necessário conhecimento pedagógico do conteúdo (pedagogical content knowledge; SHULMAN, 1986; 1987; GROSSMAN, 1990) específico sobre a leitura realizada na internet para aprender, não sendo por isso capazes de construir a pedagogia desejável e possível nesta plataforma. O reconhecimento do desalinhamento que encontrei nesta lição entre as exigências de leitura criadas pela internet e o uso de entendimentos tradicionais da leitura encontra apoio em Leu et al. (2011; 2013; KERVIN et al., 2018), que também manifestaram preocupação com as consequências dessa situação. A lição do TED-Ed analisada fundamenta empiricamente essa preocupação, mostrando a necessidade de dotar os professores do conhecimento da nova pedagogia da leitura realizada na internet com vista à construção de conhecimento.

\section{CONCLUINDO}

A principal ideia que defendo neste artigo é a da necessidade de implementação de uma nova pedagogia da leitura realizada na internet com vista à construção de conhecimento. Discuti três argumentos em cada seção do artigo, nomeadamente o do número massivo e crescente de jovens que leem na internet para aprender e que o fazem com dificuldades; a emergência de modelos teóricos específicos; e a dificuldade da implementação de uma pedagogia específica quando realizada sem o conhecimento teórico adequado. Tal como os entendo, estes argumentos convergem na defesa da necessidade de que os professores conheçam e concretizem nas suas práticas uma nova pedagogia que ensine os jovens a saber ler na internet para construir saber.

Creio que outros argumentos podem vir a ser explorados no mesmo sentido. Por exemplo, tanto o Progress in International Reading Literacy Study (PIRLS) 
(https://timssandpirls.bc.edu/) como o Programme for International Student Assessment (PISA) (http://www.oecd.org/pisa/) já incluem nos testes que administram a avaliação da capacidade de leitura realizada na internet para aprender. Por isso, também valerá a pena analisar os resultados obtidos nesses testes, a fim de constatar se apontam no sentido aqui descrito. Também pesquisas semelhantes envolvendo outras plataformas e práticas de aprendizagem semelhantes podem ser relevantes para a mesma finalidade.

Apesar da relevância desse tipo de análise, é, neste momento e na minha opinião, premente levar a cabo dois outros tipos de investigação relacionados entre si. Por um lado, creio que é necessário realizar pesquisas que aprofundem o nosso conhecimento sobre o modo como as crianças e os jovens leem na internet para aprender, procurando perguntas a respostas como as seguintes: Que gêneros leem para aprender? Que características desses textos são fáceis e difíceis de compreender? Como integram a informação representada em diferentes modos na construção de uma representação mental coerente? Que modos causam mais dificuldade? Que estratégias usam na determinação dos caminhos de leitura dos textos multimodais hiperligados? Que estratégias usam para desenvolver uma análise crítica? Creio que estas e outras perguntas incidentes na capacidade dos leitores poderiam vir a ser fundamentais no refinamento das teorias existentes, bem assim como na exploração dos caminhos pedagógicos a trabalhar com os professores.

De fato, esse seria um tipo de investigação igualmente premente. A este respeito, creio que seria fundamental desenhar processos de formação e de desenvolvimento profissional continuado que pudessem dar a conhecer os principais resultados das pesquisas empíricas e os principais desenvolvimentos teóricos que permitissem aos professores gradualmente construir o seu Pedagogical Content Knowledge sobre o assunto em discussão neste texto, transferindo esse saber para a sua prática pedagógica (e, desse modo, consolidando e validando esse saber), proporcionando aos alunos a construção de aprendizagens através da prática e do pensamento sobre a leitura na internet para aprender, mobilizando intencionalmente processos de experienciação, de conceituação, de análise e de aplicação e investigando as percepções dos alunos sobre as práticas pedagógicas vividas. Para mim, a implementação de uma nova pedagogia só será efetivamente conseguida quando for assim co-construída e validada pelos próprios agentes da sua construção. 


\section{REFERÊNCIAS}

BEZEMER, Jeff; KRESS, Gunther. Multimodality, learning and communication. A social semiotic frame. London: Routledge, 2016.

BYRNE, Jasmina; KARDEFELT-WINTHER, Daniel; LIVINGSTONE, Sonia; STOILOVA, Mariya. Global Kids Online research synthesis, 2015-2016. UNICEF Office of Research Innocenti and London School of Economics and Political Science, 2016. Disponível em: www.globalkidsonline.net/synthesis. Acesso em: 14 set. 2019.

CERVETTI, Gina; PARDALES, Michael J.;DAMICO, James S. A tale of differences: Comparing the traditions, perspectives, and educational goals of critical reading and critical literacy. Reading Online, v. 4, n. 9, 2001.

COIRO, Julie. Predicting reading comprehension on the internet: contributions of offline comprehension skills, online reading skills, and prior knowledge. Journal of Literacy Research, v. 43, p. 352-392, 2011.

COIRO, Julie. Purposeful, critical, and flexible: key dimensions of online reading and learning. In: SPIRO, R. J., DE SCHRYVER, M., HAGERMAN, M. S., MORSINK, P. M. \& THOMPSON, P. (ed.). Reading at a crossroads? Disjunctures and continuities in current conceptions and practices. New York, London: Routledge, 2015. p. 53-64.

COPE, Bill; KALANTZIS, Mary. New literacies, new learning. Pedagogies, v. 4, n.3, p. 164195, 2009.

DEWEY, John. Democracy and education. New York: MacMillan Publishing Inc., 1916.

DEWEY, John. Experience and education. New York: Collier Books, 1938.

DUARTE TORRES, Sergio; Weber, Ingmar; Hiemstra, Djoerd. Analysis of search and browsing behavior of young users on the Web. ACM Transactions on the Web, v. 8, n. 2 , 2014.

GEE, James Paul. Social linguistics and literacies. Ideology in discourse. 2 ed. London: Taylor and Francis, 1996.

GROSSMAN, Pamela. The making of a teacher: Teacher knowledge and teacher education. New York: Teachers College Press, 1990.

HALLIDAY, M. A. K. An introduction to functional grammar. London: Falmer, 1994. 
IRWIN, Judith W. Teaching reading comprehension processes. 3. ed. Boston, MA: Allyn and Bacon, 2007.

JEWITT, Carey. Multimodal "Reading" \& "Writing" on Screen. Discourse: Studies in the Cultural Politics of Education, v. 26, n. 3, p. 315-332, 2005.

JEWITT, Carey. Multimodality \& Literacy in School Classrooms. Review of Research in Education, v. 32, p. 241-267, 2008.

KALANTZIS, Mary; COPE, Bill. New Learning. Elements of a science of education. Second edition. Australia: Cambridge University Press, 2012.

KERVIN, Lisa; MANTEI, Jessica; LEU, Donald. Repositioning Online Reading to a Central Location in the Language Arts. D. Lapp \& D. Fischer (ed.). Handbook of Research on Teaching the English Language Arts, $4^{\text {th }}$ edition. London: Routledge, 2018.

KRESS, Gunther. Multimodality. A social semiotic approach to contemporary Communication. London, New York: Routledge, 2010.

KRESS, Gunther. Semiotic Work: Applied Linguistics \& a Social Semiotic Account of Multimodality. AILA Review, v. 28, p. 49-71, 2015.

KRESS, Gunther; VAN LEEUWEN, Theo. Reading images. The grammar of visual design. 2. ed. Oxon: Routledge, 2006.

KROUSTALLAKI, Dionysia; KOKKINAKI, Theano; SIDERIDIS, Giorgios D.; SIMOS, Panagiotis. G. Exploring students' affect and achievement goals in the context of an intervention to improve web searching skills. Computers in Human Behavior, v. 49, p. 156$170,2015$.

JIMURA, Koji; CAZALIS, Fabienne; STOVER, Elena R. S; POLDRACK, Russell A.. The neural basis of task switching changes with skill acquisition. Frontiers in Human Neuroscience, v. 339, p. 1-9, 2014.

LEMKE, Jay L. Travels in hypermodality. Visual Communication. Sage PublicationsSage CA: Thousand Oaks, CA, v. 1, n. 3, p. 299-325, 2002.

LEU, Donald J.; MCVERRY, J. Gregory; O'BYRNE, W. Ian; KIILI, Carita; ZAWIILINSKY, Lisa; EVERETT-CACOPARDO, Heidi; KENNEDY, Clint; FORZANI, Elena. The new literacies of online reading comprehension: Expanding the literacy and learning curriculum. Journal of Adolescent \& Adult Literacy, v. 55, n.1, p. 5-14, 2011.

LEU, Donald J.; FORZANI, Elena; RHOADS, Chris; MAYKEL, Cheryl; KENNEDY, Clint; TIMBRELL, Nicole. The new literacies of online research and comprehension: Rethinking the reading achievement gap. Reading Research Quarterly, v. 50, n. 1, p. 37-59, 2015. 
LEU, Donald J.; MAYKEL, Cheryl. Thinking in new ways and in new times about reading. Literacy Research and Instruction, v. 55, n. 2, p. 122-127, 2016.

LEU, Donald J.; KINZER, Charles K.; COIRO, Julie; CASTEK, Jill; HENRY, Laurie A. New literacies: A dual-level theory of the changing nature of literacy, instruction, and assessment. In: Alvermann, D. E., Unrau, N. \& Rudell, R. B. (ed.) Theoretical Models and Processes of Reading. 6 ed. International Reading Association, p. 1150-1181, 2013.

LEWIS, Cynthia; TIERNEY, Jessica Dockter. Mobilizing Emotion in an Urban English Classroom. Changing English: Studies in Culture and Education, v. 18 n. 3, p. 319-329, 2011.

LIM, Victor Fei. Developing a systemic functional approach to teach multimodal literacy. Functional Linguistics, v. 5, n.13, p. 1-17, 2018.

LIVINGSTONE, Sonia; CARR, John; BYRNE, Jasmina. One in Three: Internet Governance and Children's Rights. Waterloo, Ontario: Centre for International Governance Innovation and The Royal Institute of International Affairs, 2015.

LUKE, Allan; O'BRIEN, Jennifer; COMBER, Barbara. Making Community Texts Objects of Study. H. Fehring \& P. Green (ed.). Critical Literacy: A Collection of Articles from the Australian Literacy Educators' Association, Newark, DE: IRA, p. 112-123,2001.

MARTIN, John. R.; ROSE, David. Genre relations. Mapping culture. London: Equinox, 2005.

MILLS, Kathy Ann. A review of the digital turn in the New Literacy Studies. Review of Educational research, v. 80, n. 2, p. 246-271, 2010.

MILLS, Kathy Ann. Literacy theories for the digital age. Social, critical, multimodal, spatial, material and sensorial lenses. Bristol: Multilingual Matters, 2016.

NEW LONDON GROUP. A pedagogy of multiliteracies: Designing social futures. Harvard Educational Review, v. 66, p. 60-92, 1996.

NEW LONDON GROUP. A pedagogy of multiliteracies. B. Cope \& M. Kalantzis (ed.). Multiliteracies. London: Routledge, p. 19-37, 2000.

NÚCLEO DE INFORMAÇÃO E COORDENAÇÃO DO PONTO BR. Pesquisa sobre o uso da internet por crianças e adolescentes no Brasil: TIC kids online Brasil 2017= Survey on internet use by children in Brazil: ICT kids online Brazil. São Paulo: Comitê Gestor da Internet no Brasil, 2018.

PEREIRA, Íris Susana Pires (no prelo). A Multiliteracies approach to reading online to learn. Discourse analysis of a reading practice. Pedagogies. An International Journal. 
ROWSELL, Jeniffer;KRESS, Gunther;PAHL, Kate;STREET, Brian. The Social Practice of Multimodal Reading: A New Literacy Studies-Multimodal Perspective on Reading. In: Alvermann, D. E., Unrau, N. J., and Ruddel, R. B. (ed).Theoretical Models and Processes of Reading. 6 ed. Newark, DE: International Reading Association, p. 1182-1207, 2013.

SERAFINI, Frank. Reading the Visual. An introduction to teaching multimodal literacy. New York: Teachers College Press, 2014.

STAKE, Robert. Case Studies. N. Denzin \& Y. Lincoln (ed.), Handbook on qualitative Studies. California: Sage Publications Inc. Second Edition, p. 435-454, 2000.

SHULMAN, Lee S. Those who understand: knowledge growth in teaching. Educational Researcher, v. 15, n. 4, p. 4-14, 1986.

SHULMAN, Lee S. Knowledge and teaching: foundations of a new reform. Harvard Educational Review, v. 57, n. 1, p. 1-22, 1987.

VYGOTSKY, Lev. El desarrollo de los procesos psicológicos superiores. Barcelona: Crítica, 1979.

VYGOTSKY, Lev. Thought and language. Cambridge, MA: MIT Press, 1986.

WALSH, Maureen.The textual shift. Examining the reading process with print, visual and multimodal texts. Australian Journal of Language and Literacy, v. 29, n. 1, p. 24-37, 2006.

WALSH, Maureen. Worlds have collided and modes have merged: Classroom evidence of changed literacy practices. Literacy, v. 42,n. 2, p. 101-108, 2008.

WOLF, Marianne. Tales of literacy for the $21^{\text {st }}$ century. Oxford: Oxford University Press, 2016.

\section{NOTAS DE AUTORIA}

Íris Susana Pires Pereira (iris@ie.uminho.pt) é Professora no Departamento de Estudos Integrados de Literacia, Didática e Supervisão do Centro de Investigação em Educação (CIEd) / Research Centre on Education. É coordenadora do Grupo de Investigação Tecnologias, Multiliteracias e Currículo (Research Group Technologies, Multiliteracies and Curriculum).

Revista Portuguesa de Educação (Diretora adjunta): https://revistas.rcaap.pt/rpe

Como citar este artigo de acordo com as normas da revista?

PEREIRA, Íris Susana Pires. Para uma pedagogia da leitura realizada on-line: para construir conhecimento.

Texto Digital, Florianópolis, v. 15, n. 2, p. 28-56, 2019.

Contribuição de autoria

Não se aplica. 


\section{Financiamento}

Centro de Investigação em Educação, projetos UID/CED/1661/2019, Instituto de Educação, Universidade do Minho, através de fundos nacionais da FCT/MCTES PT.

\section{Consentimento de uso de imagem}

Fig. 1 - Organização genérica da lição. Disponível em: http://ed.ted.com/lessons/what-does-it-mean-to-be-arefugee-benedetta-berti-and-evelien-borgman.

Fig. 2 - Abutres vigiam as deslocações dos refugiados. Disponível em: http://ed.ted.com/lessons/what-does-itmean-to-be-a-refugee-benedetta-berti-and-evelien-borgman.

Fig. 3 - A decepção na chegada. Disponível em: http://ed.ted.com/lessons/what-does-it-mean-to-be-a-refugeebenedetta-berti-and-evelien-borgman.

Fig. 4 - Variação na visualização das personagens: de espetadores a testemunhas. Disponível em: http://ed.ted.com/lessons/what-does-it-mean-to-be-a-refugee-benedetta-berti-and-evelien-borgman

\section{Aprovação de comitê de ética em pesquisa}

Não se aplica.

\section{Licença de uso}

Este artigo está licenciado sob a Licença Creative Commons CC-BY. Com essa licença você pode compartilhar, adaptar, criar para qualquer fim, desde que atribua a autoria da obra.

\section{Histórico}

Recebido em: 29/11/2019

Aprovado em: 02/12/2019 